\title{
HUBUNGAN PERSEPSI DENGAN SIKAP KELUARGA YANG MEMILKI ANGGOTA KELUARGA MENDERITA SKIZOFRENIA DI PUSKESMAS RIAM DURIAN
}

\author{
${ }^{1}$ Rukmini Syahleman \\ ${ }^{1}$ STIKes Borneo Cendekia Medika Pangkalan Bun \\ ${ }^{1}$ Email rukminisyahleman@gmail.com
}

\begin{abstract}
ABSTRAK
Skizofrenia merupakan suatu sindrom penyakit klinis yang paling membingungkan dan melumpuhkan. Gangguan psikologis ini adalah salah satu jenis gangguan yang paling berhubungan dengan pandangan populer tentang gila atau sakit mental. Skizofrenia juga sering kali menimbulkan rasa takut, kesalahpahaman, dan penghukuman, bukan simpati atau perhatian. Penelitian ini berbentuk deskriptif korelatif dengan pendekatan cross sectional. Populasi dari penelitian ini sebanyak 21 responden. Teknik pengambilan sampel adalah total sampling. Variabel independen dari penelitian ini adalah persepsi keluarga dan variabel dependen adalah sikap keluarga. Alat ukur yang digunakan adalah lembar kuesioner, kemudian pengolahan data dimulai dari editing, coding, scoring, dan tabulating. Analisa data yang digunakan adalah uji Chi Square $(\alpha=0,05)$. Hasil penelitian didapatkan persepsi positif sebanyak 18 responden $(85,7 \%)$, sikap mendukung sebanyak 18 responden $(85,7 \%)$ dan hasil Chi Square 0,000 menunjukkan nilai $\mathrm{P}<0,05$ menggunakan aplikasi SPSS 16. Kesimpulan : berdasarkan hal tersebut dapat disimpulkan bahwa ada hubungan yang signifikan antara persepsi dan sikap keluarga yang memilki anggota keluarga menderita Skizofrenia
\end{abstract}

Kata kunci: Persepsi, Sikap

RELATIONSHIPS OF PERCEPTION AND FAMILY ATTITUDES THAT HAVE A FAMILY MEMBER SUFFERING SCIZOFRENIA IN PUSKESMAS RIAM DURIAN

\begin{abstract}
Schizophrenia is the most confusing and disabling clinical disease syndrome. This psychological disorder is one type of disorder that is most associated with popular views about insanity or mental illness. Schizophrenia also often causes fear, misunderstanding, and punishment, not sympathy or concern. This research is in the form of correlative descriptive with cross sectional approach. The population of this study was 21 respondents. The sampling technique is total sampling. The independent variable of this research is family perception and the dependent variable is family attitude. The measuring instrument used was a questionnaire sheet, then data processing started from editing, coding, scoring, and tabulating. Analysis of the data used is the Chi Square test $(\alpha=0.05)$. The results obtained positive perceptions of 18 respondents (85.7\%), supportive attitudes of 18 respondents (85.7\%) and Chi Square results of 0,000 showed a value of $P<0.05$ using the SPSS 16 application. Conclusion: based on this it can be concluded that there is a
\end{abstract}


significant relationship between perceptions and family attitudes that have family members suffering from Schizophrenia

Keywords: Perceptions, attitudes

\section{PENDAHULUAN}

Skizofrenia merupakan suatu sindrom penyakit klinis yang paling membingungkan dan melumpuhkan. Gangguan psikologis ini adalah salah satu jenis gangguan yang paling berhubungan dengan pandangan populer tentang gila atau sakit mental. Skizofrenia juga sering kali menimbulkan rasa takut, kesalahpahaman, dan penghukuman, bukan simpati atau perhatian

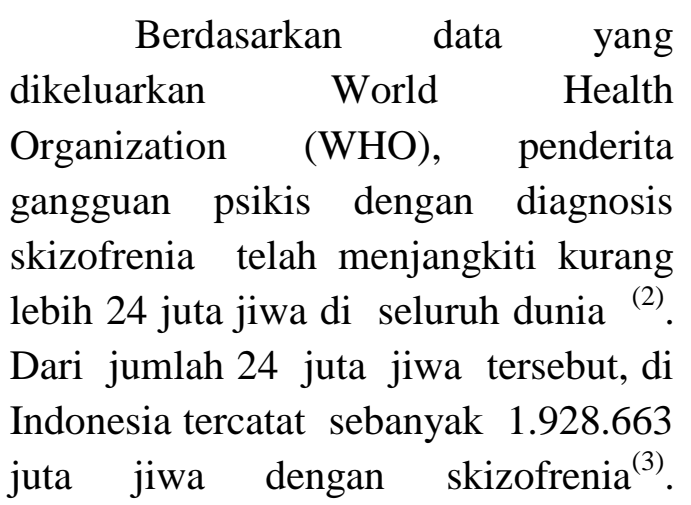
Keadaan orang dengan skizofrenia di Indonesia digambarkan pada Konferensi Nasional Skizofrenia yang diadakan pada tanggal 14 hingga 16 Oktober 2010. Dalam konferensi tersebut, terdapat penyajian data mengenai orang dengan skizofrenia di Indonesia yang telah mencapai sekitar 2,5 persen dari total penduduk Indonesia.

Skizofrenia menyerang jati diri seseorang, memutus hubungan yang erat antara pemikiran dan perasaan serta mengisinya dengan persepsi yang terganggu, ide yang salah, dan konsepsi yang tidak logis. Skizofrenia menyentuh semua aspek kehidupan dari orang yang terkena. Episode akut dari skizofrenia ditandai dengan waham, halusinasi, pikiran yang tidak logis, pembicaraan yang tidak koheren, dan perilaku yang aneh Peneliti pada Medical Research Council's Social Psychiatry Unit di London mengadakan penelitian yang hasilnya menyimpulkan bahwa pasien yang tinggal bersama keluarga yang penuh kritik atau menggunakan kalimat yang berbelit-belit ketika berkomunikasi lebih sering kambuh. Keluarga yang menggunakan komunikasi yang menyimpang terhadap anggota keluarga skizofrenia dapat mengganggu kemajuan proses penyembuhan pasien dan berhubungan dengan munculnya kekambuhan pada pasien skizofrenia.

Prevalensi skizofrenia di Indonesia adalah $0,3-1 \%$. Apabila diperkirakan penduduk Indonesia sekitar 200 juta jiwa, maka diperkirakan sebanyak 2 juta jiwa menderita skizofrenia, sedangkan di daerah Surakarta, prevalensi berdasarkan data rekam medik RSJD Surakarta (2010) terdapat sebanyak 2.381 pasien skizofrenia, yang terdiri dari 33 pasien skizofrenia hebefrenik, 10 skizofrenia katatonik, 333 tak terinci, 1 pasien depresi pasca skizofrenia, residual 158, simpleks 4 
pasien, lainnya 1.047 pasien, YTT 29 pasien.

Skizofrenia sampai saat ini masih belum dipahami oleh sebagian besar masyarakat. Masyarakat masih menganggap atau sekedar tahu bahwa skizofrenia adalah gangguan atau sakit jiwa dan biasa disebut gila. Pandangan dan penilaian yang demikian ini menyebabkan masyarakat menganggap rendah, kotor, dan hina bagi penderita. Kebanyakan masyarakat selalu menunjukkan sikap yang acuh dan tidak peduli kepada penderita gangguan jiwa, bahkan ada juga yang memperlakukan mereka seperti binatang.

Berdasarkan data diatas maka peneliti ingin mengetahui lebih lanjut tentang “ Hubungan persepsi dengan sikap keluarga yang memilki anggota keluarga yang menderita skizofrenia di Puskesmas Riam Durian"

\section{METODE PENELITIAN}

Penelitian ini berbentuk deskriptif korelatif dengan pendekatan cross sectional. Populasi dari penelitian ini sebanyak 21 responden. Teknik pengambilan sampel adalah total sampling. Variabel independen dari penelitian ini adalah persepsi keluarga dan variabel dependen adalah sikap keluarga. Alat ukur yang digunakan adalah lembar kuesioner, kemudian pengolahan data dimulai dari editing, coding, scoring, dan tabulating. Analisa data yang digunakan adalah uji Chi Square $(\alpha=0,05)$.

\section{HASIL PENELITIAN}

Tabel 1 Distribusi frekuensi berdasarkan umur

\begin{tabular}{clrc}
\hline N & Umur & $\begin{array}{l}\text { Freku } \\
\text { ensi }\end{array}$ & $\begin{array}{l}\text { Persent } \\
\text { ase }\end{array}$ \\
\hline 1 & $<20$ Thn & 9 & 42.9 \\
2 & $20-40$ Thn & 7 & 33.3 \\
3 & $>40$ Thn & 5 & 23.8 \\
\hline \multicolumn{2}{c}{ Total } & 21 & 100 \\
\hline
\end{tabular}

Sumber: Data primer 2018

Tabel 1 Berdasarkan tabel 5.1 hampir separuh responden berumur kurang dari 20 tahun sebanyak 9 responden ( 42,9 $\%$ )

Tabel 2 Distribusi frekuensi berdasarkan pendidikan

\begin{tabular}{l|r|r}
\hline \multicolumn{1}{c|}{ Pendidikan } & Jumlah & Prosentase \\
\hline dasar & 10 & 47.6 \\
\hline menengah & 11 & 52.4 \\
\hline Total & 21 & 100.0 \\
\hline
\end{tabular}

Sumber: Data primer 2018

Berdasarkan tabel 2 separuh responden berpendidikan menengah sebanyak 11 responden $(52,4 \%)$.

Tabel 3 Distribusi frekuensi berdasarkan pekerjaan

\begin{tabular}{c|c|c}
\hline Pekerjaan & Jumlah & Prosentase \\
\hline petani & 6 & 28.6 \\
\hline pedagang & 4 & 19.0 \\
\hline swasta & 6 & 28.6 \\
\hline irt & 5 & 23.8 \\
\hline Total & 21 & 100.0 \\
\hline
\end{tabular}

Sumber: Data primer 2018

Berdasarkan tabel 3 pekerjaan responden petani dan swasta masingmasing sebanyak 6 responden $(28,6 \%$ ) . 
Tabel 4 Distribusi frekuensi berdasarkan informasi kesehatan

\begin{tabular}{c|c|c}
\hline Info Kesehatan & Jumlah & Prosentase \\
\hline sudah & 21 & 100.0 \\
\hline
\end{tabular}

Sumber: Data primer 2018

Berdasarkan tabel 4 seluruh responden sudah menerima informasi tentang kesehatan sebanyak 21 responden ( $100 \%)$.

Tabel 5 Distribusi frekuensi berdasarkan asal informasi kesehatan

\begin{tabular}{c|c|c}
\hline $\begin{array}{c}\text { Asal Info } \\
\text { Kesehatan }\end{array}$ & Jumlah & Prosentase \\
\hline Fakes & 21 & 100.0 \\
\hline \multicolumn{2}{l}{ Sumber: Data primer 2018}
\end{tabular}

Berdasarkan tabel 5 seluruh responden sudah menerima informasi tentang kesehatan dari petugas kesehatan sebanyak 21 responden $(100 \%)$.

Tabel 6 Distribusi Frekuensi Persepsi Keluarga Pasien Skizofrenia di Puskesmas Riam Durian

\begin{tabular}{c|c|c}
\hline Persepsi & Jumlah & Prosentase \\
\hline Positif & 18 & 85.7 \\
\hline Negatif & 3 & 14.3 \\
\hline Total & 21 & 100.0 \\
\hline
\end{tabular}

Sumber: Data primer 2018

Berdasarkan Tabel 6 lebih dari separuhnya memiliki persepsi positif sebanyak 18 responden ( $85,7 \%$ ).

Tabel 7 Distribusi Frekuensi Sikap Keluarga Pasien Skizofrenia di Puskesmas Riam Durian

\begin{tabular}{c|c|c}
\hline Sikap & Jumlah & Prosentase \\
\hline Mendukung & 18 & 85.7 \\
\hline Tidak & 3 & 14.3 \\
\hline
\end{tabular}

\begin{tabular}{c|c|c}
\hline mendukung & & \\
\hline Total & 21 & 100.0 \\
\hline $\begin{array}{c}\text { Sumber: Data primer } 2018 \\
\text { Berdasarkan tabel }\end{array}$ & hampir
\end{tabular}
seluruh responden telah melaksanakan sikap mendukung sebanyak 18 responden $(85,7 \%)$.

Tabel 8 distribusi frekuensi persepsi dan sikap Keluarga Pasien Skizofrenia di Puskesmas Riam Durian

\begin{tabular}{|l|l|l|l|}
\hline Persepsi & Sikap & total \\
\cline { 2 - 3 } & $\begin{array}{l}\text { Menduku } \\
\text { ng }\end{array}$ & $\begin{array}{l}\text { Tidak } \\
\text { menduku } \\
\text { ng }\end{array}$ & \\
\hline Positif & $18(100 \%)$ & 0 & 18 \\
\hline Negatif & 0 & $3(100 \%)$ & 3 \\
\hline Total & 18 & 3 & 21 \\
\hline \multicolumn{2}{l}{ Chi Square $=0,000$} \\
Sumber: Data primer 2018
\end{tabular}

Berdasarkan tabel 8 keluarga melaksanakan persepsi positif dengan sikap mendukung sebanyak 18 responden ( $85,7 \%$ ). Hasil Uji Chi Square Persepsi Keluarga dengan Sikap pada pasien Skizofrenia di Puskesmas Riam Durian memiliki nilai Asymp.Sig 0,000 yang artinya < dari $\alpha$ 0,05 sehingga $\mathrm{H}$ nol di tolak dan Ha di terima yaitu Ada hubungan Persepsi Keluarga dengan sikap keluarga terhadap pasien skizofrenia di Puskesmas Riam Durian.

\section{PEMBAHASAN}

\section{Persepsi Keluarga Pasien Skizofrenia Di Puskesmas Riam Durian}

Berdasarkan Tabel 5.6 lebih dari separuhnya memiliki persepsi positif sebanyak 18 responden $(85,7 \%)$. 
Proses seseorang mengetahui beberapa hal melalui panca inderanya. Persepsi manusia terdapat perbedaan sudut pandang dalam penginderaan. Ada yang mempersepsikan sesuatu itu baik atau persepsi yang positif maupun persepsi negatif yang akan mempengaruhi tindakan manusia yang tampak atau nyata. Setiap orang mempunyai kecenderungan dalam melihat benda yang sama dengan cara yang berbeda-beda. Perbedaan tersebut bisa dipengaruhi oleh banyak faktor, diantaranya adalah pengetahuan, pengalaman dan sudut pandangnya. Persepsi baik positif maupun negatif ibarat file yang sudah tersimpan rapi di dalam alam pikiran bawah sadar kita. File itu akan segera muncul ketika ada stimulus yang memicunya, ada kejadian yang membukanya.

Berdasarkan tabel 5.2 separuh responden berpendidikan menengah sebanyak 11 responden ( 52,4\%). Tidak dapat dipungkiri bahwa semakin tinggi pendidikan seseorang, semakin mudah pula mereka menerima informasi, dan pada akhirnya pengetahuan yang dimiliki kebanyaakan semakin banyak. Pada aspek psikologis atau mental, taraf berpikir seseorang semakin matang dan dewasa Namun dengan sejalan peningkatan jenjang pendidikan juga akan membawa perubahan cara berpikir seseorang. Tidak dapat dipungkiri bahwa semakin tinggi pendidikan seseorang, semakin mudah pula mereka menerima informasi, dan pada akhirnya pengetahuan yang dimiliki kebanyaakan semakin banyak.

Berdasarkan tabel 5.3 pekerjaan responden petani dan swasta masing- masing sebanyak 6 responden ( $28,6 \%$ ). Lingkungan pekerjaan dapat membuat seseorang memperoleh pengalaman dan pengetahuan, baik secara langsung maupun tidak langsung. Pekerjaan adalah kegiatan yang harus dilakukan, terutama untuk menunjang kehidupannya dan kehidupan keluarga.

Berdasarkan tabel 5.4 seluruh responden sudah menerima informasi tentang kesehatan sebanyak 21 responden $(100 \%)$. komunikasi yang baik responden dengan tenaga kesehatan akan berdampak pesat terhadap kepatuhan pada program terapi sehingga dengan demikian juga berdampak pada persepsi keluarga pasien Skizofrenia.

Berdasarkan tabel 5.5 seluruh responden sudah menerima informasi tentang kesehatan dari petugas kesehatan sebanyak 21 responden (100\%). Motivasi dari petugas kesehatan merupakan faktor lain yang dapat mempengaruhi kepatuhan. Motivasi mereka terutama berguna saat pasien menghadapi bahwa perilaku sehat yang baru tersebut merupakan hal penting. Begitu juga mereka dapat mempengaruhi perilaku pasien dengan cara menyampaikan antusias mereka terhadap tindakan tertentu dari pasien, dan secara terus menerus memberikan penghargaan yang positif bagi pasien yang telah mampu beroreintasi dengan program pengobatannya

\section{Sikap Pada Pasien Skizofrenia Di Puskesmas Riam Durian}

Berdasarkan tabel 5.7 hampir seluruh responden telah melaksanakan 
sikap mendukung sebanyak 18 responden ( $85,7 \%$ ). Peran keluarga adalah mampu mengenal masalah kesehatan, mampu membuat keputusan tindakan, mampu melakukan perawatan pada anggota keluarga yang sakit, mampu memodifikasi lingkungan rumah, dan mampu memanfaatkan pelayanan kesehatan yang ada. Sikap yang optimal akan memberi dampak pada status kesehatan yang optimal juga. Sikap yang sehat merupakan cerminan pola hidup keluarga yang senantiasa memperhatikan dan menjaga kesehatan seluruh anggota keluarga. Sikap yang sehat adalah semua perilaku yang dilakukan atas kesadaran sehingga anggota keluarga atau keluarga dapat menolong dirinya sendiri di bidang kesehatan dan berperan aktif dalam kegiatan-kegiatan kesehatan di masyarakat. Mencegah lebih baik daripada mengobati.

Berdasarkan tabel 5.1 hampir separuh responden berumur kurang dari 20 tahun sebanyak 9 responden (42,9\%). Dengan bertambahnya umur seseorang akan mengalami perubahan aspek fisik dan psikologis (mental). Secara garis besar, pertumbuhanfisik terdiri atas empat kategori perubahan yaitu perubahan ukuran, perubahan proporsi, hilangnya ciri-ciri lama dan timbulnya ciri-ciri baru. Perubahan ini terjadi karna pematangan fungsi organ. Pada aspek psikologis atau mental, taraf berpikir seseorang semakin matang dan dewasa

Berdasarkan tabel 5.2 separuh responden berpendidikan menengah sebanyak 11 responden $(52,4 \%)$. Responden yang berada di tingkat menengah lebih mudah untuk menerima dan memahami infomasi sehingga responden mau untuk mendukung sikap terhadap kesembuhan pasien skizofrenia. Tingkat Pendidikan berarti bimbingan yang diberikan seseorang kepada orang lain agar dapat memahami sesuatu hal. Tidak dapat dipungkiri bahwa semakin tinggi pendidikan seseorang, semakin mudah pula mereka menerima informasi, dan pada akhirnya pengetahuan yang dimiliki kebanyaakan semakin banyak

Berdasarkan tabel 5.3 pekerjaan responden petani dan swasta masingmasing sebanyak 6 responden $(28,6 \%)$. Lingkungan pekerjaan dapat membuat seseorang memperoleh pengalaman dan pengetahuan, baik secara langsung maupun tidak langsung. Pekerjaan adalah kegiatan yang harus dilakukan,terutama untuk menunjang kehidupannya dan kehidupan keluarga

Berdasarkan tabel 5.4 seluruh responden sudah menerima informasi tentang kesehatan sebanyak 21 responden $(100 \%)$. Kemudahan untuk memperoleh suatu informasi dapat mempercepat seseorang mempunyai pengetahuan yang baru. Sebaliknya jika informasi sulit didapat, seseorang akan cenderung malas untuk mencari informasi

Berdasarkan tabel 5.5 seluruh responden sudah menerima informasi tentang kesehatan dari petugas kesehatan sebanyak 21 responden (100\%). Motivasi dari petugas kesehatan merupakan faktor lain yang dapat mempengaruhi kepatuhan. Motivasi mereka terutama berguna saat 
pasien menghadapi bahwa perilaku sehat yang baru tersebut merupakan hal penting. Begitu juga mereka dapat mempengaruhi perilaku pasien dengan cara menyampaikan antusias mereka terhadap tindakan tertentu dari pasien, dan secara terus menerus memberikan penghargaan yang positif bagi pasien yang telah mampu beroreintasi dengan program pengobatannya

\section{Hubungan Persepsi Keluarga Dengan Sikap Pada Pasien Skizofrenia Di Puskesmas Riam Durian}

Berdasarkan tabel 5.8 keluarga melaksanakan sikap yang mendukung dengan persepsi keluarga positif sebanyak 18 responden $(85,7 \%)$. Sikap yang mendukung kesembuhan pasien skizofrenia memiliki tujuan yaitu meningkatkan pengetahuan, kesadaran, kemauan dan kemampuan masyarakat agar hidup bersih dan sehat serta masyarakat termasuk swasta dan dunia usaha berperan serta aktif mewujudkan derajat kesehatan yang optimal

Berdasarkan tabel 5.9 Uji Chi Square Persepsi Keluarga dengan Sikap Pada Pasien Skizofrenia di Puskesmas Riam Durian memiliki nilai Asymp.Sig 0,000 yang artinya $<$ dari $\alpha$ 0,05 sehingga $\mathrm{H}$ null di tolak dan $\mathrm{Ha}$ di terima yaitu Ada hubungan Persepsi Keluarga dengan Sikap Pada Pasien Skizofrenia di Puskesmas Riam Durian. Petugas kesehatan yang juga bertindak sebagai seorang motivator memilik beban terhadap tugas yang di emban, petugas kesehatan harus benar- benar teliti sikap keluarga dan program terapi.

\section{KESIMPULAN DAN SARAN}

\section{Kesimpulan}

1. Persepsi Keluarga Pasien

Skizofrenia Di Puskesmas Riam Durian adalah positif

2. Hampir seluruh responden memiliki sikap mendukung Pasien Skizofrenia di Puskesmas Riam Durian

3. Ada hubungan Persepsi Keluarga dengan Frekuensi Sikap Pada Pasien Skizofrenia di Puskesmas Riam Durian

\section{Saran}

1. Keluarga pasien Skizofrenia tetap mempertahankan persepsi yang sudah dilaksanakan bahkan jika memungkinkan meningkatkan prilaku yang sudah ada.

2. Petugas kesehatan tetap menjaga komunikasi yang baik kepada keluarga dan masyarakat di sekitar Puskesmas Riam Durian agar lingkungan di sekitar terbebas dari penyakit Skizofrenia.

\section{DAFTAR PUSTAKA}

Jeste, D.V. \& Mueser, K.T., 2008, Clinical Handbook of Schizophrenia, Guilford Press, New York.

WHO., 2010. The World Health Report 2010. http://www.who.int./whr/2010/en /index.html Akses 18 Desember 2012 
Bloch, S., Scmukler, G.I., Herrman, H., \& Colussa, S. (1995). Counseling Caregivers of Relatives with Schizophrenia: Themes, Interventions, and Caveats. Family Process, Vol. 34, 413-425

Nevid dkk. 2005. Psikologi Abnormal. Jilid 2. Jakarta: Erlangga

Arif, I. S. (2006). Skizofrenia: Memahami Dinamika Keluarga Pasien. Bandung: Rafika Aditama.

Nolen, Hoeksema, S. (2004). Abnormal Pyschology (3rd ed.). New York, NY: McGraw-Hill.

Wiramihardja, Sutarjo. (2005). Pengantar Psikologi Abnormal. Bandung : Refika Aditama

Fawcett, C.S. 1993. Family Psychiatric Nursing. St. Louis: Mosby-Year Book Inc.

Lestari, F. S. 2011. Hubungan Persepsi Keluarga Tentang Gangguan Jiwa dengan Sikap Keluarga Kepada Anggota Keluarga Ynag Mengalami Gangguan Jiwa di Rumah Sakit Jiwa Surakarta. Skripsi. Surakarta: Jurusan Keperawatan Fakultas Ilmu Kesehatan Universitas Muhammadiyah Surakarta

Sadock BJ, Sadock VA. Kaplan \& Sadock's Synopsis of Psychiatry. Behavior Sciences/Clinical Psychiatry. 10thed. Lippincott Williams \& Wilkins, 2007.

Kazadi N. J. B, dkk. (2008). Factors as Sociated With Relaps in Schizophrenia. Jakarta: Rineka Cipta.
Durand, V. M, Barlow, D.H. (2007). Essentials of Abnormal Psychology. Yogyakarta: Pustaka Pelajar

Maramis, W. F. (1995). Catatan Ilmu Kedokteran Jiwa. Surabaya : Universitas Airlangga Press

Buchanan. (2005). Mengenal Prilaku Abnormal. Yogyakarta : Kanisius.

Davidson G, Dkk (2006). Psikologi Abnormal. Jakarta : Rajawali Press

PPDGJ III.(1993). Pedoman Penggolongan dan Diagnosis Gangguan Jiwa di Indonesia III : cetakan pertama. Jakarta : Departemen Kesehatan 